\title{
Effectiveness of Gamification on Students' Online Activity in a Distance Learning Class
}

\author{
Esther Ida Krisanti ${ }^{1}$ and Rendy Vally ${ }^{2}$ \\ Distance Learning Department, Universitas Pelita Harapan, Banten, Indonesia ${ }^{1,2}$ \\ \{esther.krisanti@uph.edu ${ }^{1}$,rendy.vally@lecturer.uph.edu²
}

\begin{abstract}
In the field of education, gamification is expected to be one of elements that can enhance student motivation to study. Although there are several studies abroad that show positive correlation between gamification and student activity, there are still minimum research about this topic in Indonesian context, specifically in distance learning environment. This research is aimed to see the effects of gamification on student online activity in a distance learning class. Distance learning environment provides a different characteristic of students who usually already have worked thus the effectiveness of gamification on them is still questionable. To see the effectiveness of gamification in term of students' online activity, experimental research is conducted to compare the results between two groups: control group (non-gamified class) and experimental group (gamified class). To minimize bias, this research does not use access restriction. By letting them access freely without restriction, a more authentic result is more likely to be obtained because students access their course voluntarily. As result, the numbers of online activities from both categories were compared and analyzed using quantitative approach with comparative method to see the effects of gamification on student online activity. The findings are interesting because it shows that the gamified class has higher number of activities in all course components but the difference between two classes are not significant. The result also shows that on certain dates the number of nongamified class is higher than the gamified class.
\end{abstract}

Keywords: Distance Learning; Effectiveness; Gamification; Online Activity

\section{Introduction}

Digitalization of content is increasingly needed in higher education in Indonesia, especially in distance learning context. Based on interview with Minister of Research, Technology, and Higher Education which is cited by medcom.id in 2019, there are about 15-20 of 4.741 universities in Indonesia that offer distance learning class [1].

One of the challenges in content digitalization and online class is how to increase the level of students' activity (accessing materials, doing assessments, discussing certain topics with lecturers and peers) in an online class which has different characteristics with a regular (faceto-face) class. The students of this type of class usually have worked. Based on the study conducted by Arkorful and Abaidoo [2], one of the benefits of online learning is its usage that 
allows self-pacing. Self-pacing means that the students may study at his or her own pace because this type of online class usually use asynchronous way such as discussion forum, lecturing notes that are recorded in a video, and assessments that can be done in a more flexible way. Students may even choose their own speed whether slow or quick. In this sense, they may successfully follow all the learning scenarios that the lecturers set in online course or they may fail to follow some or even all the learning scenarios. Therefore, engaging students in this type of class is one of the challenges the lecturers face. To accommodate this, one of the strategies that is expected to enhance students' activity (online or face-to-face) is gamification.

Gamification is applied by using game design elements in non-game contexts [3]. This concept is seen as a powerful tool by increasing engagement in a target activity and influence behaviour [4]. A lot of literatures prove that the presence of game elements in a class may lead to greater usage of online learning contents. For example, Poondej and Lerdpornkulrat [5] provides empirical support for gamification in education and conclude that students clearly valued the engagement of gamified learning activities. Lee and Hammer [6] also stated that gamification may create an environment that gives joyful experience to students.

Looking at the potential benefits of gamification, this research is conducted to test whether gamification also beneficial in distance learning context. Although many literatures stated that gamification can produce a greater amount of use of online teaching materials, the effect of gamification in a distance learning environment is still in question due to the different students' profile. Hence a research question is aroused: Is gamification in a distance learning class effective to increase the level of students' online activity? By knowing the effectiveness of gamification in distance learning environment, it may provide insights for the lecturers to design a more effective course and to explore the gamification concept itself.

\section{Method}

This research is conducted using experimental research to compare online activity between two groups: control group and experimental group. The control group (class A) is an online class without gamification feature while the experimental group (class B) has gamification features. Both groups are students from distance learning class in Universitas Pelita Harapan who take undergraduate degree in communication science major. Group A (31 students) consists of $97 \%$ workers and 3\% full-time students while group B (31 students) consists of $94 \%$ workers and $6 \%$ full-time students. The method to do this research is explained in the following section. First, to compare the results between the control group and experimental group, one-way ANOVA test is conducted to compare the means of self-regulated level between two groups. Self-regulated level is used because it may affect the students in how they regulate themselves to stick on learning plan in an online class. To measure this, a short self-regulation questionnaire from Short Self-Regulation Questionnaire (SSRQ) developed by Carey, D. J. Neal, and S. E. Collins [7] is distributed to both groups. After conducting one-way ANOVA test, it shows the F value is 1.32 , which is lower than the critical value of 4.00 . This indicates that the two groups are not statistically different from each other. Since these two groups are equivalent in the context of self-regulated level, these two groups can be compared.

Second, the environments for class A and class B are set in Moodle as the learning management system. Both groups are treated with same subject, same material, and same lecturer. The only difference is that class B is equipped with gamification features which include activity completion checkbox, Level up!, and completion progress. A special consideration is taken in this research regarding access restriction. This feature is not used in both groups 
because it tends to produce bias result. By letting them access freely without restriction, we may get a more authentic result of student access that are done voluntarily.

Third, to see the effects of gamification features to student online activity, this research uses comparative method to compare student online activity for both groups. Based on the research conducted by Zorilla, Garcia, and Alvarez [8], the method for assessing students' online activity can be flexible (in term of parameter to measure the activity: time, hits, or a combination of both), extensible (in term of the measured activity), and independent from learning management system / LMS (can be generated from data registered in LMS). Furthermore, according to Douglas and Alemanne [9], much or all the interaction in online course is assymetric, therefore activities such as logging in to symmetric class session, participation in discussion forum, and reading materials can be used to define the participation of an online course. Therefore, this research uses the amount of hits (such as view, submit, post) as the indicator of students' online activity. This data is derived from log reports in Moodle.

Results from both classes are compared and analyzed using quantitative approach with comparative method to see the effects of gamification to students' online activity. One-way ANOVA test is also conducted to determine if there are any statistically significant differences between the means of students' online activity in two classes.

\section{Result and Discussion}

\section{a) Comparison of Students' Online Activity per Course Component in Control Group and Experimental Group}

The control group (Class A / non-gamified) and experimental group (Class B / gamified) are monitored in 7 sessions. The $7^{\text {th }}$ session is mid-term exam. The data collected is not limited to "view" activity, but all records related to course access. After 7 sessions, all data from log reports are collected. The data are categorized into 6 components which are file, assignment, file submissions, forum, quiz, and system. File is related to number of views of file, assignment and file submission are related to assessment where students have to submit file(s), forum is related to discussion about certain topic, quiz is related to assessment where students have to answer questions provided by the lecturers, while system is the sum of the course viewed and course user report viewed. The result is presented in the following chart:

\begin{tabular}{|c|c|c|c|c|c|c|}
\hline \multirow[t]{2}{*}{$\begin{array}{r}5000 \\
4000 \\
3000 \\
2000 \\
1000 \\
0\end{array}$} & \multicolumn{5}{|c|}{$\square$} & \multirow[b]{2}{*}{ System } \\
\hline & File & Assignment & $\begin{array}{c}\text { File } \\
\text { submissions }\end{array}$ & Forum & Quiz & \\
\hline Class A (Non-gamified) & 532 & 1912 & 174 & 959 & 561 & 3023 \\
\hline Class B (Gamified) & 812 & 2012 & 198 & 1159 & 751 & 3834 \\
\hline Difference & 280 & 100 & 24 & 200 & 190 & 811 \\
\hline$\simeq \mathrm{Cla}$ & Non & ied) & ss B (Gam & & ence & \\
\hline
\end{tabular}

Fig. 1. Comparison of Students Online Activities for Each Component 
Fig. 1 shows that overall class B (gamified) has higher number of events or activities done by students. The result also shows that the most different score of the activities is related to system component which is sum of the course viewed and course user report viewed, followed by file, forum, quiz, and assignment. This finding is interesting since it may reveal that because quiz and assignment are mandatory, the number of activities related to those two activities is not much different while the non-mandatory activities shows greater number of differences. Therefore, in this context, the gamification may encourage students in gamified class to access or participate more in online activities including the non-mandatory ones than other students in non-gamified class. This finding is consistent with other research conducted by Khalil, Ebner, and Admiraal [10], which shows that the gamified online course increases the level of students attention and engagement. This finding also supports the "non-restricted" rule used in this research. By letting them access freely without restriction, it reveals a more authentic result of student access that are done voluntarily. This is also consistent with the findings by Cahyani [11], in which she recommends that the student participation should be voluntary to make sure that the participants can feel the "game-like" activity.

\section{b) Comparison of Weekly Students' Online Activity}

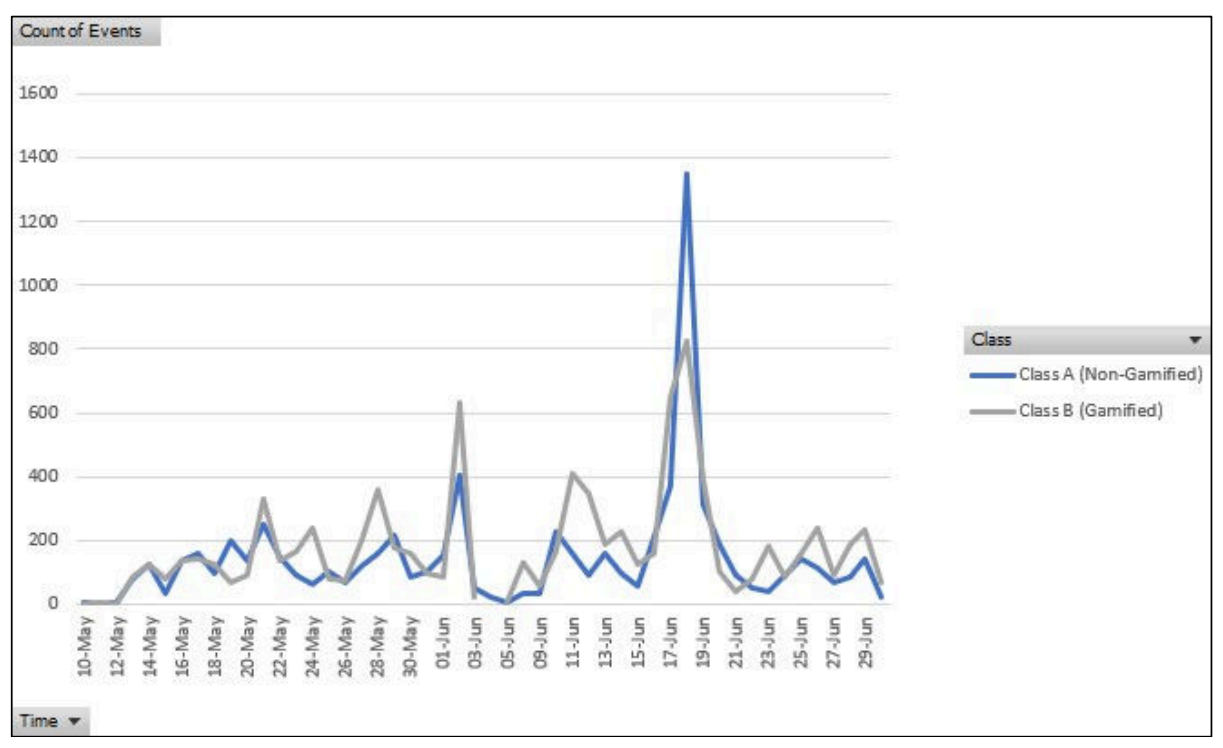

Fig. 2. Comparison of Students Online Activities Over Time

Fig. 2 shows that the weekly students' online activity does not look significantly different. The total number of students' online activity is 7161 and 8766 for class A and class B, respectively. On average, class B (experimental group) has higher number of activities but interestingly it also has lower number of activities on certain dates. There are several insights from this graph:

1. Total number of students' online activity in class B (experimental group) is higher than class A (control group).

2. In term of total number of activities over time, the student online activity in experimental group is higher on average. But, interestingly, on certain date (June 18), the number of 
activities in control group (class A) is much higher compared to experimental group (class B).

After further investigation, the data shows that there was an assignment for mid-term examination that was due on June 18. There is a greater difference between mid-term examination submissions on June 18. The number of quiz-related activities before June 18 is also higher in experimental group than in control group. This result is interesting because it may reveal other insights that can be investigated in further research about the effect of gamification on students' motivation to finish their tasks before the due date.

This finding may also reveal further question about classroom management. Classroom management includes elements of classroom discipline. According to Chandra [12], proper classroom management may help to promote class control and conducive teaching learning environment. Therefore, the result of this finding which shows that almost $50 \%$ of the students in gamified class has submitted their mid examination submissions before the due date may be correlated with the students' discipline and classroom management. The research conducted by Carlson, Harris, and Harris [13] (although in different context with this research) shows that the students see that the gamification classroom management system was fun and can help them in term of classroom performance and classroom strategy. Therefore, it is likely that the presence of gamification may help students to help themselves in creating their own strategy to follow the course instructions and finish the assessments.

c) Comparison of the Means of Students' Online Activity in Control Group and Experimental Group

One-way ANOVA is conducted to see if there are any statistically significant differences between the means of students' online activity in two classes. The result is presented below:

Table 1. One-Way Anova Test for Means Of Students' Online Activity

\begin{tabular}{lccc}
\multicolumn{4}{c}{ SUMMARY } \\
\hline Groups Count & Sum & Average & Variance \\
\hline Class A (Non- gamified) & 31.007161 .00 & 231.00 & 16358.33 \\
Class B (Gamified) & 31.008766 .00 & 282.77 & 22597.38 \\
\hline
\end{tabular}

\begin{tabular}{lcccccc}
\multicolumn{9}{c}{ ANOVA } \\
\hline Source of Variation & $\boldsymbol{S S}$ & $\boldsymbol{d} \boldsymbol{f}$ & $\boldsymbol{M S}$ & $\boldsymbol{F}$ & $\boldsymbol{P}$-value & $\boldsymbol{F}$ crit \\
\hline Between Groups & 41548.79 & 1.00 & 41548.79 & 2.13 & 0.15 & 4.00 \\
Within Groups & 1168671.42 & 60.00 & 19477.86 & & & \\
Total & 1210220.21 & 61.00 & & & & \\
\hline
\end{tabular}

The one-way ANOVA test result that can be seen in Table I shows that F value (2.13) is lower than the critical value of 4.00. This means that the two groups are not statistically different from each other in term of their number of online activities. This result answers the second result which shows that the weekly number of online activities does not look significantlydifferent.

This finding may provide insights that although gamification can contribute positively to students' learning, the design of the course still takes an important part to make it more effective. Based on Skinner's Reinforcement Theory which is cited by Amutan [14], educators have to be aware that the external environment should be designed effectively and positively so that it may work to motivate the students. Kim also stated that if carefully designed, gamification may create fun and joy in its implementation that match with players's own desires and values [4]. As Kutluk and Gulmez [15] suggest, a qualified education should have a well-planned course 
design. Without a well-planned course design, gamification may not produce significant difference. The challenge here is the readiness of the educators to adapt with gamification in online course. According to Bingimlas [16], teachers may face major barriers such as lack of confidence and lack of competence. Therefore, training and support should be prepared to help the educators to adapt with ICT skills. According to Ghavifekr [17], in addition to formal training and support, educators may also study the issue and challenges related to ICT to help them become successful technology users.

\section{Conclusion}

Many literatures show positive impact of gamification in the field of education. By applying gamification in class, educators may encourage students to participate more. Therefore, this concept can be seen as a promising approach that can enhance student motivation to study. This research is aimed to see the effectiveness of gamification on student online activity (accessing materials, doing assessments, discussing certain topics with lecturers and peers) in a distance learning class. Distance learning environment provides a different characteristic of students who usually already have worked thus the effectiveness of gamification on them is still in question. After collecting data from control group (non-gamified class) and experimental group (gamified class), there are three important insights that can be concluded from this research. First, from experimental group (gamified class) shows relatively higher number of activities than control group (non-gamified class). The higher number of activities are calculated based on online events of items such as accessing file, submitting to assignments, doing quizzes, posting in forum, and accessing class in general. Second, the number of activities in experimental group shows significantly lower number of activities on due date of midtermexamination. It turns out that almost $50 \%$ of the students in gamified class have submitted their tasks before the due date. Therefore, the number of students submitting their tasks on the due date of mid-term examination is lower in experimental group. This finding is interesting because it may reveal other insights or trigger further research questions about effect of gamification on class management or eagerness of students to finish tasks before due date. Third, the control group and experimental groups are not statistically different from each other in term of their number of online activities. Therefore, gamification in course design should be well-planned to enhance the effectiveness of gamification to students' online activity.

In summary, this research shows that the application of gamification in distance learning class has positive result on students' online activity, but the effect is not significant in this case study. It is also important to note that access restriction is not used in both classes. Therefore, the result in this study shows result based on voluntary participation in both classes. Further research can take issue about designing gamification in an online course, correlation between gamification and class management, or gamification as a media to communicate rewards and appreciation from lecturers or teachers to students.

\section{Acknowledgement}

We thank Online Education Directorate of Universitas Pelita Harapan for letting us use the learning management system data used in Universitas Pelita Harapan. We would also like to show our gratitude to head of communication department in Universitas Pelita Harapan, Stella Stefany who provides feedback for the presentation of this research. 


\section{References}

[1] "Baru 20 Perguruan Tinggi Terapkan e-Learning." [Online]. Available: https://www.medcom.id/pendidikan/news-pendidikan/8kowxwWk-baru-20-perguruantinggi- terapkan-e-learning. [Accessed: 30-Oct-2019].

[2] V. Arkorful and N. Abaidoo, "The role of e-learning, advantages and disadvantages of its adoption in higher education," Int. J. Instr. Technol. Distance Learn., vol. 12, no. 1, pp. 29-42, 2015.

[3] S. Deterding, R. Khaled, L. E. Nacke, and D. Dixon, Gamification: Toward a Definition. .

[4] K. Bohyun, "Gamification in Education and Libraries," Libr. Technol. Rep., vol. 51, no. 2, pp. 20-28, 2015.

[5] C. Poondej and T. Lerdpornkulrat, "The development of gamified learning activities to increase student engagement in learning," Aust. Educ. Comput., vol. 31, no. 2, pp. 1$16,2016$.

[6] J. Lee and J. Hammer, "Gamification in Education: What, How, Why Bother?," Acad. Exch. Q., vol. 15, no. 2, p. 146, 2011.

[7] K. B. Carey, D. J. Neal, and S. E. Collins, "A psychometric analysis of the selfregulation questionnaire," Addict. Behav., 2004.

[8] M. Zorrilla, D. García, and E. Álvarez, "An approach to measure student activity in learning management systems," CSEDU 2010 - 2nd Int. Conf. Comput. Support. Educ. Proc., vol. 2, pp. 21-28, 2010.

[9] I. Douglas and N. D. Alemanne, "Monitoring Participation in Online Courses," Proc. 8th Int. Conf. Inf. Technol. Based High. Educ. Training, Kumamoto, Japan, no. July, pp. 315-320, 2007.

[10] M. Khalil, M. Ebner, and W. Admiraal, "How can gamification improve MOOC student engagement?," Proc. 11th Eur. Conf. Games Based Learn. ECGBL 2017, no. October, pp. 819-828, 2017.

[11] A. D. Cahyani, "Gamification approach to enhance students engagement in studying language course," MATEC Web Conf., vol. 58, no. June, 2016.

[12] R. Chandra, "Classroom management tools for effective teaching," Int. J. Educ. Psychol. Res., 2015.

[13] J. Carlson, R. Harris, and K. Harris, "Coin Counter: Gamification for Classroom Management.," Inf. Syst. Educ. J., vol. 15, no. 5, pp. 4-14, 2017.

[14] K. I. Amutan, "A Review of B.F. Skinner's 'Reinforcement Theory of Motivation,"” Int. J. Res. Educ. Methodol., 2014.

[15] F. A. Kutluk and M. Gulmez, "A Research about Distance Education Students' Satisfaction with Education Quality at an Accounting Program," Procedia - Soc. Behav. Sci., vol. 46, pp. 2733-2737, 2012.

[16] K. A. Bingimlas, "Barriers to the successful integration of ICT in teaching and learning environments: A review of the literature," Eurasia J. Math. Sci. Technol. Educ., vol. 5, no. 3, pp. 235-245, 2009.

[17] S. Ghavifekr, T. Kunjappan, and L. Ramasamy, "Teaching and Learning with ICT Tools: Issues and Challenges from Teachers' Perceptions," Malaysian Online J. Educ. Technol., vol. 4, no. 2, pp. 38-57, 2016. 